\title{
INFORMATION-INSTRUMENTAL TOOLS OF MICROWAVE AND OPTICAL ENVIRONMENTAL MONITORING
}

\author{
VLADIMIR F. KRAPIVIN ${ }^{1}$, COSTICĂ NITU ${ }^{2}$, FERDENANT A. MKRTCHYAN ${ }^{1}$, VLADIMIR \\ YU. SOLDATOV ${ }^{1}$, ANDA SABENA DOBRESCU ${ }^{2}$ \\ ${ }^{1}$ Kotelnikov Institute of Radioengineering and Electronics, Russian Academy of Sciences, Moscow, Russian \\ Federation, vkrapivin_36@mail.ru \\ ${ }^{2}$ Department of Automatic Control and System Engineering, University Politehnica of Bucharest, Bucharest, \\ Romania, cnitu_ubp2001@yahoo.com
}

\begin{abstract}
Informational capabilities of microwave and optical tools for environmental monitoring are assessed when they are located on the mobile platforms. This paper presents new approach to the combined use of microwave and optical sensors as basic elements of environmental monitoring system architecture oriented on the registration of information about characteristics of hydrological and hydrochemical objects. Geoecological information-modeling system (GIMS) is proposed as the GIS generalization with regard to the solution of series of the tasks arising in the agriculture, water quality assessment and operational diagnostics of stressful natural processes. Algorithms and models are characterized to be as the GIMS components that realize the decision making procedures providing the monitoring regime optimization and reconstruction of spatial image of the controlled environmental object using anisotropic data fluxes. Functional characteristics of several mobile platforms equipped by microwave radiometers are given as tools for the monitoring of hydrological objects. Two optical instruments are represented and their functions are characterized.

Keywords: mobile platform, microwave radiometer, model, GIS, GIMS, soil moisture, algorithm, spectroellipsometer, spectral image.
\end{abstract}

\section{INTRODUCTION}

There exist many tools for monitoring and analyzing the information delivered by different sources such as cartography sources, remote sensing systems, aerial and satellite imagery, etc. One of effective tools is geophysical information systems (GIS) that help to combine this information creating the overlapping layers that can be analyzed interactively within one spatial structure.

Traditionally GIS-technology provides the easy-to-use for users control tool of the monitoring object state and is efficient procedure for the combination of many-factors information about the studied environmental objects. In general, GIS-technology has restrictions when it is needed to solve complex monitoring task including a creation of dynamic image of the environmental subsystem using the episodic and uncertain monitoring data. Really, basic defect of the GIS-technology is that it can not to form the multi-aspect prognosis of environmental sub-system. Moreover, the GIS-technology has not adaptation function [1,2].

Fundamental progress in the GIS-technology was made in [1-5] where new geoecological information-modeling system (GIMS) was theoretically established and practically used. GIMS-technology allows the prognosis of the environmental sub-system state basing on the episodic monitoring data. General conception of the GIMS- technology was developed by Nitu et al. [2]. Key element of the GIMS-technology is remote sensing testing of maximal possible parameters of controlled geo-ecosub-system. Namely such combination of empirical and theoretical GIMS-technology components allows the operative assessment of current and forecasting environmental changes within the regional or global scales where studied sub-system has effect.

GIMS-technology provides constructive tools for the management of information from various sources supporting operative assessments of the current and forecasting environmental changes. The GIMS-technology unites existing information sources coordinating and optimizing information fluxes what leads to the economically effective monitoring system synthesis. Furthermore, universal GIMS structures can be created to be adapted to the specific environmental monitoring problem what facilitates a solution of this problem [6-8].

\section{THE GIMS-TECHNOLOGY DESCRIPTION}

Main idea of the GIMS-technology is a development of the Big Data approach when an analysis of information from multiple data sources is needed to assess and forecast the environmental object or process state. The GIMS-technology focus is integration of algorithms, models, databases and functions of mobile platforms to synthesize the monitoring system that can balance the remote sensing 
and on-site measurements and optimize information and cost of this system. Conceptual scheme of the GIMS-technology is represented in Figure 1 and its functions are explained in Figure 2 and listed in Table 1.

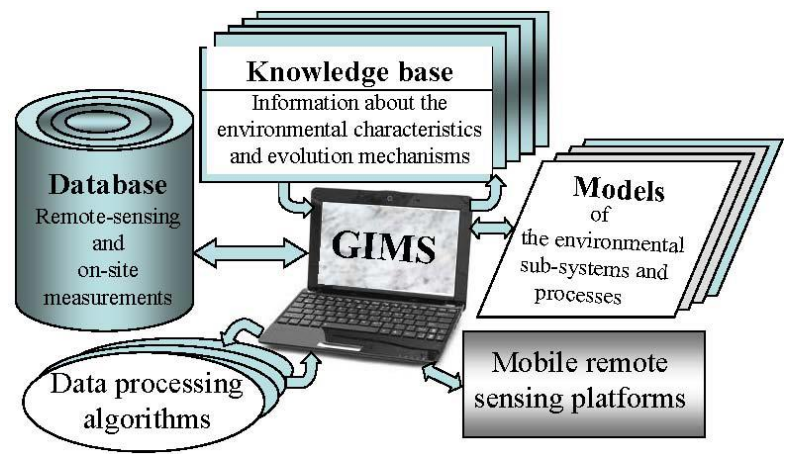

Figure 1. Conceptual scheme of the GIMS-technology structure in the framework of mobile environmental monitoring.

Main problem and difficulties of environmental monitoring consist in the studied object dynamics and impossibility to have regular measurements of its characteristics in the all space and time. That is why, optimal use of remote sensing and on-site data is principal GIMS function when operative detection and prognosis of the evolution of negative environmental processes is needed. The GIMS functions realize measuring, descriptive, interpretive, explanatory, forecasting, and criterion operations.

Table 1. The GIMS blocks and their functions.

\begin{tabular}{|c|l|}
\hline Block & \multicolumn{1}{|c|}{ Description on the block function } \\
\hline PABDC & Planning and analysis of big data clouds. \\
\hline SABDF & $\begin{array}{l}\text { Synchronous analysis of big data fluxes } \\
\text { using space-time interpolation and ex- } \\
\text { trapolation methods. }\end{array}$ \\
\hline EAS & Estimation of the atmosphere state. \\
\hline CASPF & $\begin{array}{l}\text { Classification and assessment of the state } \\
\text { of the soil-plant formations. }\end{array}$ \\
\hline ESWM & $\begin{array}{l}\text { Evaluation of the state of the water me- } \\
\text { dium. }\end{array}$ \\
\hline MGBC & $\begin{array}{l}\text { Modeling of the global biogeochemical } \\
\text { cycles. }\end{array}$ \\
\hline MP & Modeling of the photosynthesis. \\
\hline MDP & Modeling of demographic processes. \\
\hline CCM & Climate change modeling. \\
\hline MHP & Modeling of the hydrological processes. \\
\hline SIT & $\begin{array}{l}\text { Solution of inverse tasks arising in re- } \\
\text { mote sensing and optical observations. }\end{array}$ \\
\hline FGIS & Formation of the GISs. \\
\hline DESD & $\begin{array}{l}\text { Detection of ecological and sanitary dis- } \\
\text { turbances in the environment }\end{array}$ \\
\hline UIS & User intelligent support. \\
\hline
\end{tabular}
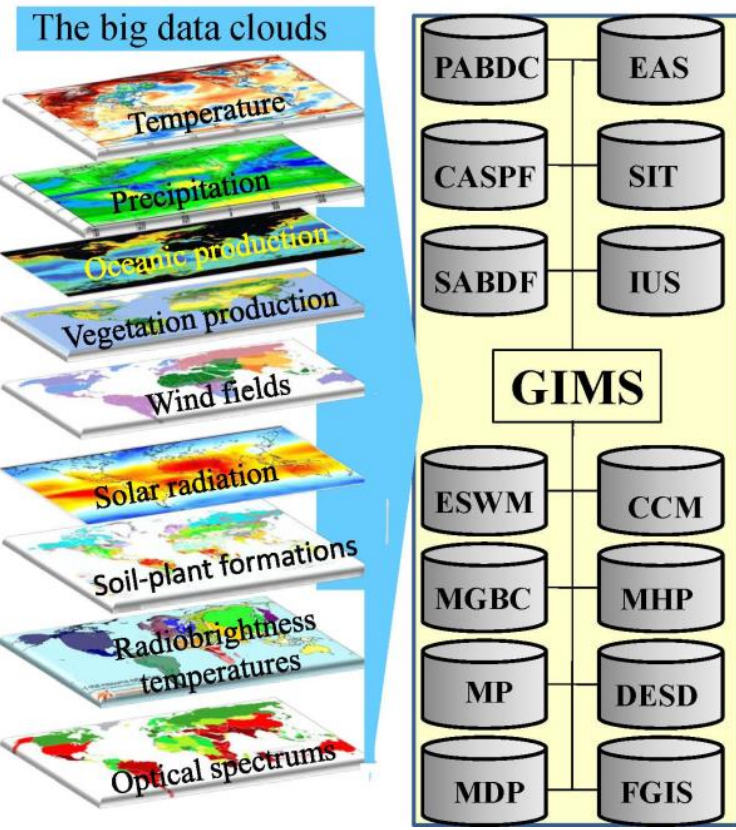

Figure 2. The GIMS-technology block-diagram. List of the GIMS blocks is represented in Table 1 .

The GIMS universality is expressed in its adaptability to the monitoring object. Symbolically this function is explained in Figure 3. The GIMS database contains matrix structures $\Xi_{j}=\left\|a_{i s}^{j}\right\|$ as identifiers of the environmental elements where $a_{i s}^{j}$ corresponds $j$ th element located in pixel $\Omega_{i s}$ of spatial digitization of the monitoring object. Block SABDF analyses initial choice of spatial scales by the latitude and longitude and using algorithms for space-temporal interpolation adopts GIMS to the user's task.

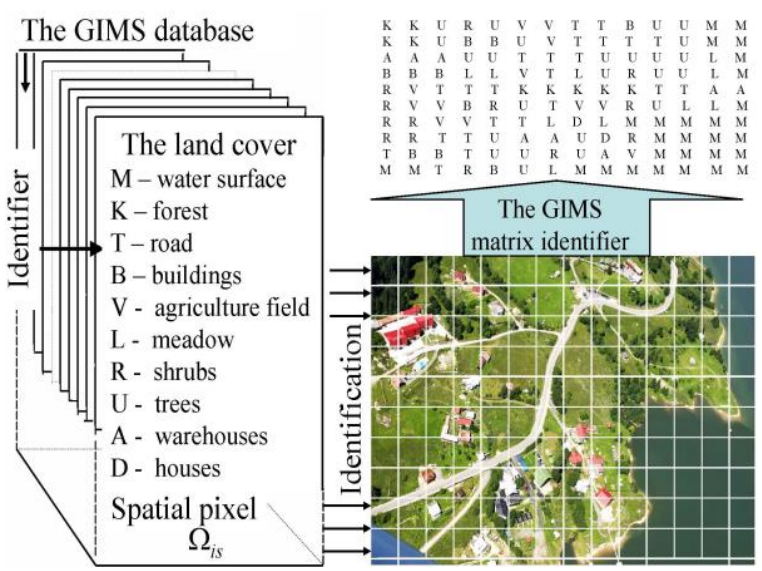

Figure 3. The GIMS identification procedure.

\section{THE MICROWAVE TOOLS}

The GIMS-technology is widely used for the solution of numerous tasks connected with the environment diagnostics by means of present microwave technologies the instrumental tools of which are based on mobile platforms of different scales [1,5]. Theoretical problems of radiometry remote sensing of land surfaces, atmosphere and oceanic areas were detailed studied and 
developed [7,9]. A possibility of the monitoring information acquisition depends on the models describing physical and geometrical characteristics of intrinsic emission (heat), diffusion and reflection mechanisms of active and passive radiation. Commonly, environmental remote sensing systems are equipped by the radiometers with spectral range from $0.3 \mu \mathrm{m}$ to $1.3 \mathrm{~m}$ including sub-regions: ultra high frequency (UHF), super-high frequency (SHF) and very high frequency (VHF). The SHF region sensors are used for the equipping the remote sensing platforms as monitoring system elements when regional problems are solved:

- a control of the soil moisture distribution for the agriculture applications;

- a detection of the water leakages from channels, sewerage systems and other lines;

- a detection of the under-flooding sites including railroads, urban zones, and other objects; and

- a detection of forested zones where forest fire is possible.

Really used SHF region is function of solved task. Usually SHF wavelengths are divided by three bands: millimeter $(1-10 \mathrm{~mm})$, centimeter $(1-10 \mathrm{~cm})$ and decimeter $(10-130 \mathrm{~cm})$. The most traditional bands are L-band $(15.8-63 \mathrm{~cm})$ and P-band $(63-100 \mathrm{~cm})$. These bands are important for the Earth surface monitoring when microwave emissions of various land covers are registered. One of important task is the synthesis of models and algorithms that could descript in details the soil and vegetation characteristics for their use in different biosphere models [6].

Real spectral range choosing for the environmental object monitoring is defined by many circumstances mainly connected with an absorption and dispersion of the electromagnetic waves by the atmosphere as well as their interaction with surface covers and aquatic objects. Basic defect of the microwave radiometric observations is a dependence of spatial resolution on the altitude of mobile platforms. To solve arising here problems, the required models are made. One of such models is represented in Figure 4. There exist different realizations of this block-diagram [1,9]. Microwave models of the soil-plant formations describe the Lband radiation transfer through leaves or conifers elements that usually represented as cylinders or cycles distributed with some law.

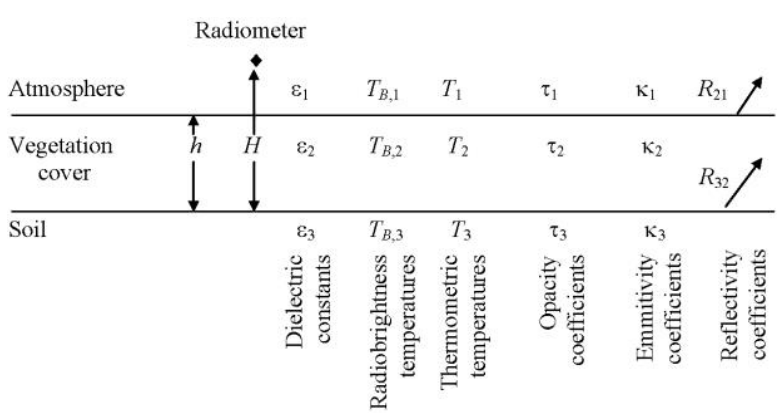

Figure 4. Block-diagram of the vegetation cover microwave model.
Figures 5-8 show general view of the platforms that can be equipped with microwave radiometers. These mobile platforms deliver data to the GIMS that provides the soil moisture assessment in the range from 0.02 to $0.5 \mathrm{~g} / \mathrm{cm}^{3}$ with the error no more $0.07 \mathrm{~g} / \mathrm{cm}^{3}$. Depth of the ground waters is measured in the range from $0.05 \mathrm{~m}$ to $5 \mathrm{~m}$ with the error 0.3-0.6 $\mathrm{m}$. Vegetation cover biomass can be measured in the range for 3 $\mathrm{kg} / \mathrm{m}^{2}$ with the error $0.2 \mathrm{~kg} / \mathrm{m}^{2}$. The MACS platform can carry one radiometer of the $1.4 ; 1.67$ or $5 \mathrm{GHz}$ and operate in the distance of $160 \mathrm{~km}$.

The GIMS-technology allows the spatial image reconstruction of studied environmental object with detection of stressful situations or zones of their possible beginning such as the increased temperature in the forested area, rockslide zone, beginning the water leakage, the oil product and pollutant spills on the water or soil surfaces. Application of concrete platform is defined by the monitoring task. The IMARC and IL-18 orient to the large-scale experiments, MACS and Miramap sensor can use for the regional monitoring, and Rover platform is usually used in the local measurements.
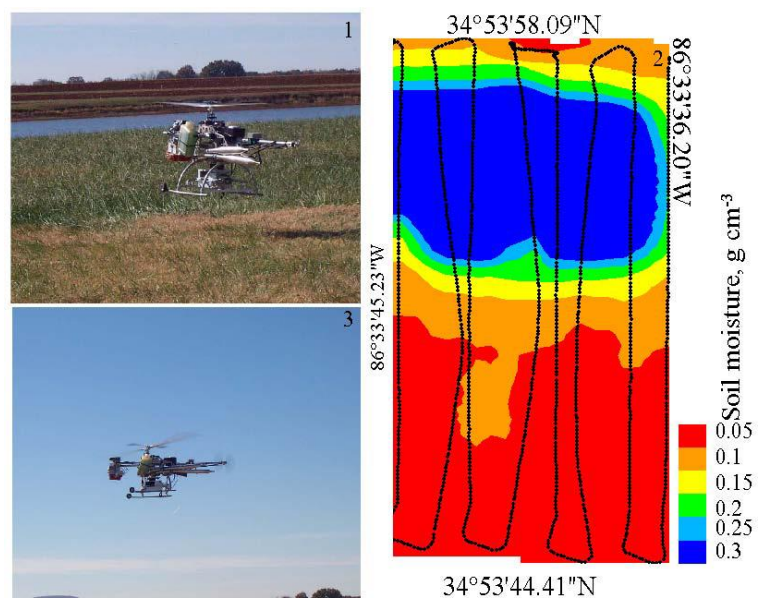

Figure 5. Photographs of the Microwave Autonomous Copter System (MACS) and monitoring results [1]. Nomination: 1 - general view of the MACS during landing; 2 - a fragment of monitoring results; 3 - the MACS is flying.

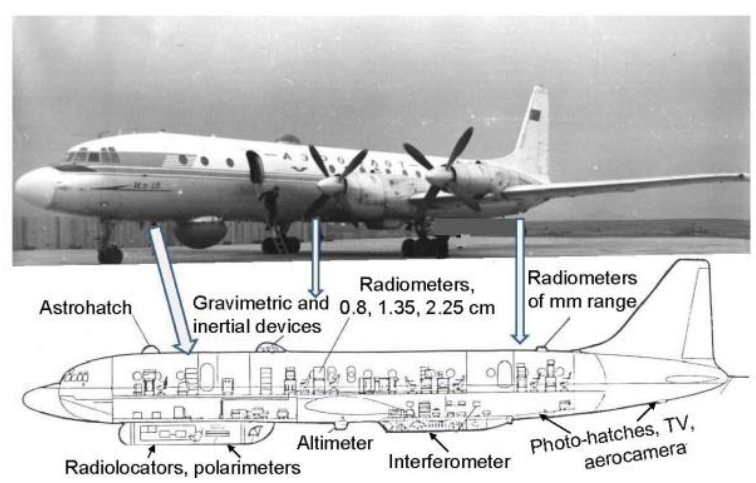

Figure 6. Multi-functional monitoring platform IL-18 equipped with microwave and optical sensors.

The GIMS-based platforms are equipped with radiometric systems of different bands depending on the 
solved task. Functional characteristics of these platforms are given in Tables 2 and 3. These equipped platforms provide the measurements:

- soil moisture content in range $10-500 \mathrm{~kg} / \mathrm{m}^{3}$ with absolute error $10 \%$;

- underground moisture up to depth $5 \mathrm{~m}$;

- contours of water seepage in the zone of hydrotechnical constructions and railway embankments;

- biomass of aquatic vegetation;

- above ground plant biomass;

- surface temperature anomalies; and

- water salinity or mineralization and contaminant concentrations.

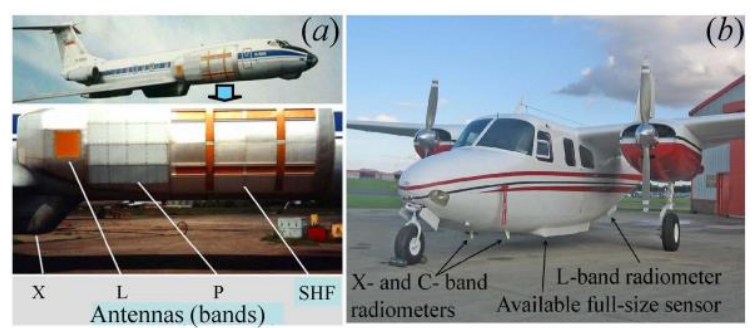

Figure 7. Intelligent Multi-frequency Airborne polarimetric Radar Complex (IMARC) (a) equipped with radiometers and radiometric system "Radius" of bands:

$X(3.9 \mathrm{~cm}), \mathrm{L}(23 \mathrm{~cm})$, P $(68 \mathrm{~cm})$ и $\operatorname{SHF}(2.54 \mathrm{~m})$ [5].

Miramap sensor aircraft (b). Sensor specification includes digital photo camera, lidar scanner, passive microwave scanner, thermal camera, lidar (3-D) land surface relief measurer [1]

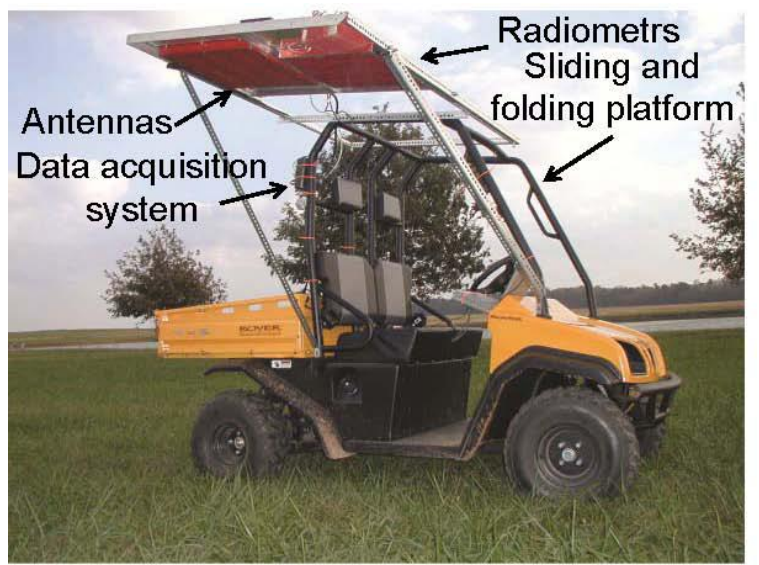

Figure 8. General view $(a)$ and working stage of the mobile platform "Rover" [1].

Table 2. Miramap product specifications.

\begin{tabular}{|l|c|c|}
\hline \multicolumn{1}{|c|}{ Parameter } & $\begin{array}{c}\text { Operating } \\
\text { range }\end{array}$ & Max error \\
\hline Soil moisture, $\mathrm{g} / \mathrm{cm}^{3}$ & $0.02-0.5$ & 0.07 \\
\hline $\begin{array}{l}\text { Depth to water table, } \\
\mathrm{m}\end{array}$ & $0.05-5$ & $0.3-0.6$ \\
\hline Plant biomass, $\mathrm{kg} / \mathrm{m}^{2}$ & $0-3$ & 0.2 \\
\hline $\begin{array}{l}\text { Contaminant } \\
\text { concentrations, }(\mathrm{ppt})\end{array}$ & $1-30$ & $1-5$ \\
\hline
\end{tabular}

Table 3. Characteristics of the rover and copter systems.

\begin{tabular}{|c|c|c|}
\hline Parameter & \multicolumn{2}{|c|}{ Value } \\
\cline { 2 - 3 } & Rover platform & Copter system \\
\hline $\begin{array}{c}\text { Frequen- } \\
\text { cies }\end{array}$ & $\begin{array}{c}1.41,1.67, \text { and } \\
5 \mathrm{GHz}\end{array}$ & $1.41 \mathrm{or} 5 \mathrm{GHz}$ \\
\hline $\begin{array}{c}\text { Polariza- } \\
\text { tion }\end{array}$ & $\mathrm{H}$ or V & $\mathrm{H}$ or V \\
\hline Antennas & $\begin{array}{c}19.7^{\prime \prime} \times 19.7^{\prime \prime} ; \\
16.3^{\prime \prime} \times 16.3^{\prime \prime} ; \\
7.9^{\prime \prime} \times 6.5^{\prime \prime}\end{array}$ & $\begin{array}{c}\text { Flat panels w } / 30^{\circ} \\
3 \mathrm{~dB}\end{array}$ \\
\hline $\begin{array}{c}\text { Incidence } \\
\text { angle }\end{array}$ & $\begin{array}{c}\text { Fixed angles } 0- \\
30^{\circ} \text { off nadir }\end{array}$ & $\begin{array}{c}\text { Fixed angles } 0-30^{\circ} \\
\text { off nadir }\end{array}$ \\
\hline Sensitivity & $0.5 \mathrm{~K}$ & $0.5 \mathrm{~K}$ \\
\hline Beamwidth & $30^{\circ}$ & $30^{\circ}$ \\
\hline Weight & $12 \mathrm{~kg}$ & $6 \mathrm{~kg}$ \\
\hline $\begin{array}{c}\text { Power re- } \\
\text { quired }\end{array}$ & $30 \mathrm{VA}$ & $15 \mathrm{VA}$ \\
\hline
\end{tabular}

\section{OPTICAL INSTRUMENTS}

There exist many water monitoring instruments for surface water and groundwater applications. Nevertheless, this monitoring regime needs in the innovative solutions leading to the more operative regimes of decision making with maximal reliability [11.12]. Such real-time water-quality decision is supported by the GIMS when in-situ measurements are combined with simulation model of regional hydrological regime. Optical sensors use different principles for applications in freshwater, estuary, coastal, and ocean environments. Mainly these principles are based on the spectral absorption properties depending on the concentration of chemical contaminant. The GIMS-technology provides the water quality assessment for any spatial heterogeneous reservoir using restricted series of the insitu measurements. This function is realized in adaptive identifiers represented in Figures 9 and 10. These tools are based on the GIMS-technology and are possessed by the adaptation possibility to the studied reservoir environment as well as are learned to recognize spectral images. Learning procedure consists in the formation of the database of spectral etalons of the water solutions.

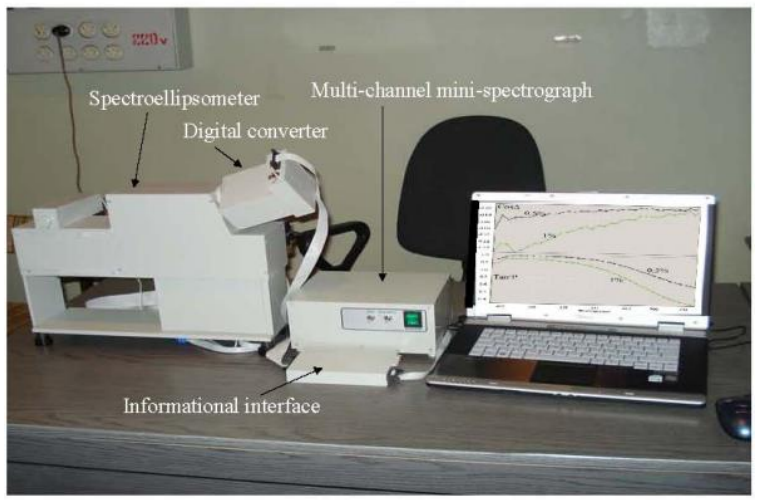

Figure 9. 35-channels spectroellipsometric instrumental system for the water quality monitoring [10]. 


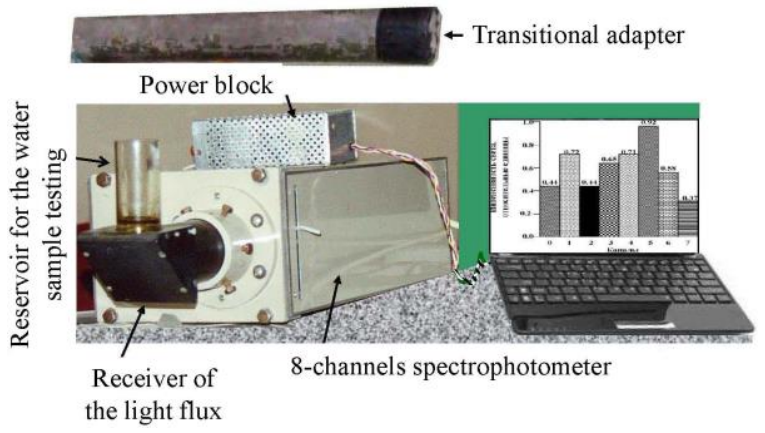

Figure 10. An adaptive identifier-spectrophotometer and its interface elements.

Optical tools deliver specters that characterize the water quality reflecting the changes of light fluxes during their propagation across the water environment or are reflected from the water surface. In any case, spectral image of the water reservoir is formed to be as indicator of its quality characteristics. Figure 11 shows an example of spectroellipsometric spectrum.

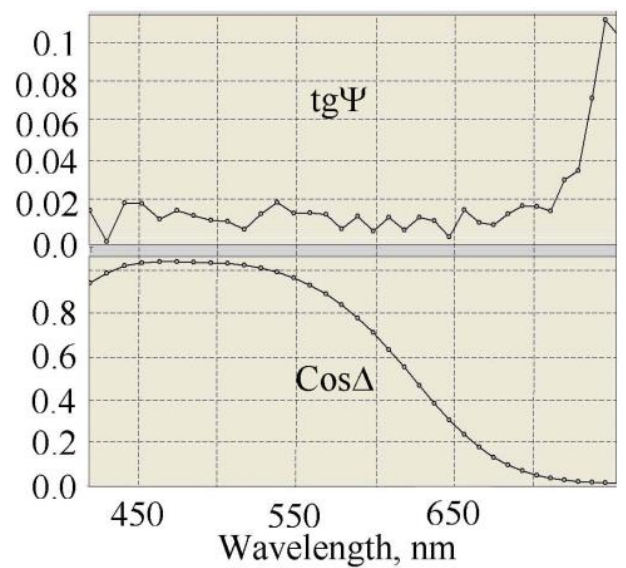

Figure 11. Spectral image of the $\mathrm{CuSO}_{4}$ water solution of 10 percents. $\Psi$ and $\Delta$ are spectroellipsometric angles.

One of the GIMS function (block SIT) is the recognition of spectral images and assessment of chemical contaminant concentration. This procedure is realized by several algorithms including cluster analysis, transformation of the specters into vector space and evaluation distance between specters in the database of spectral images. The GIMS selects algorithm that provides minimal error.

\section{THE GIMS-BASED MONITORING}

Information-instrumental tools considered here for environmental monitoring are oriented to the efficient solution of many important tasks arising in agriculture, forestry, road building, water quality diagnostics, and etc. $[2,4]$. The GIMS-technology provides universal tools for solution many of these tasks basing on the adaptation procedure. Figure 12 explains all stages of the GIMS-based environmental monitoring. The GIMS architecture is oriented on the synthesis of the environmental object image basing on existing a-priory information with a subsequent modernization of the object model and data processing algorithms. Basic GIMS structure has series of models and algorithms providing the description of atmospheric, hydrological, hydrochemical, geophysical, and ecological processes. For example, regional water balance model [6] allows the simulation of water regime taking into seasonal variability in the river outflow, snow cover, and vegetation cover.

The GIMS user choices spatial discrete structure of the studied environmental object basing on pixels $\Delta \varphi \times \Delta \lambda$ where $\varphi$ and $\lambda$ are latitude and longitude, respectively. Matrix structures are synthesized for the GIMS adaptation to the environmental object taking into account its spatial and subject structures. Experts fix trace of measuring system and on-site points for the calibration of radiometers. After that spatial reconstruction of the environmental object is realized and its precision is evaluated. Unsatisfactory result needs the additional remote sensing measurements using other trace of mobile platform. This procedure continues up to satisfactory result. A comparison of forecasting results with on-site measurements in selected pixels allows the temporal regime of monitoring procedure. It is shown in Figure 12. Figure 13 shows possible precisions of such monitoring regime after heavy rain. Soil moisture and litter water content evolve during four days with the precision of 5-10\%. Figures $13(a, b)$ show the differences between forecasting values and in-situ measurements after four days (a) and two days (b), respectively. Figure $13 \mathrm{c}$ shows integral precisions on the studied area (about $100 \mathrm{~km}^{2}$ ).

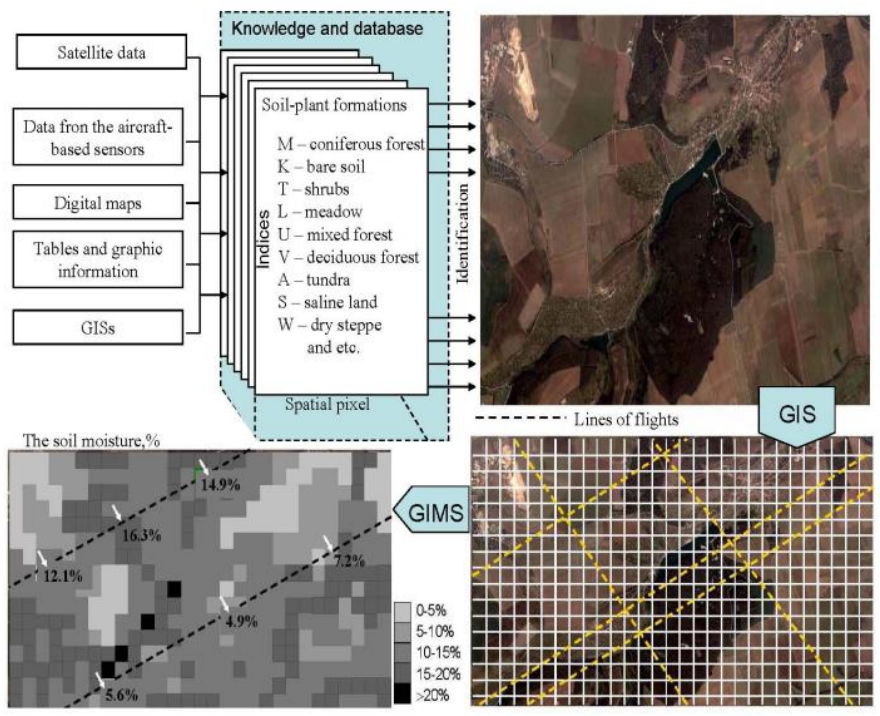

Figure 12. GIMS-technology provides spatial image reconstruction of the area characteristics basing on the trace microwave measurements.

These results of microwave monitoring show that GIMS-technology can be the base for the synthesize of information-instrumental tools with functions of ecological risk assessment and identification of different environmental disasters that can origin in hydrology, agriculture, ecology, forestry, etc. Choice of concrete mobile platform depends on the specific task and area for monitoring. 


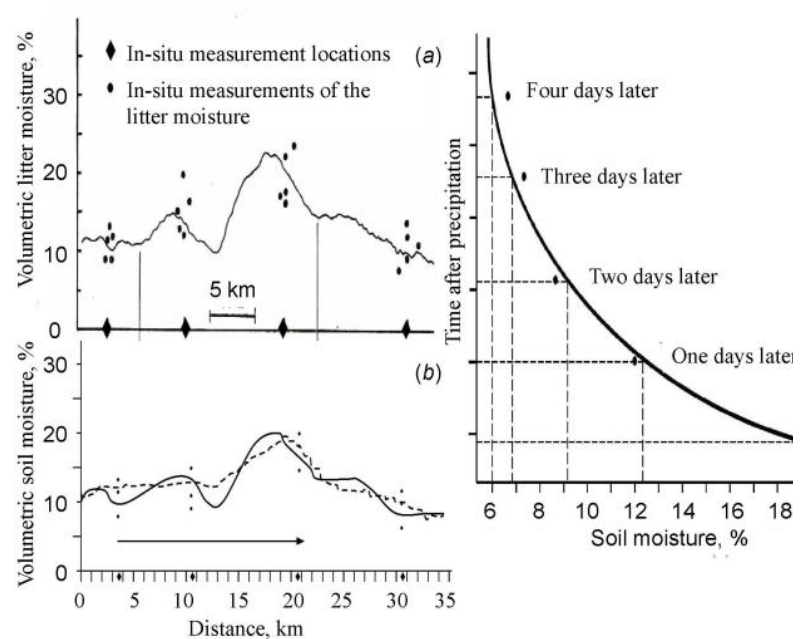

Figure 13. In-situ and remote srnsing measurements (a,b) and prognosis of the soil moisture $\odot$ with the using GIMS-based Miramap platform in the Rusenski Lom region of Bulgaria [5].

Combined use of microwave and optical tools make more precise of monitoring results when the water surfaces are studied concerning the pollutant spots and their parameters. When it is needed to assess the water quality characteristics for total area of hydrological object taking into consideration of its depth, spectrophotometers and spectroellipsometers are used [13-15]. Figure 9 and 10 represent such instruments that deliver spectral images of studied reservoir.

Environmental monitoring experience when microwave and optical tools were used have partly described in monograph [1]. For example, the GIMS approach to the assessment of the water quality of reservoirs of South Vietnam allows the correlation between precisions and frequency of measurements what given rule for the monitoring regime (Figure 14 and 15).

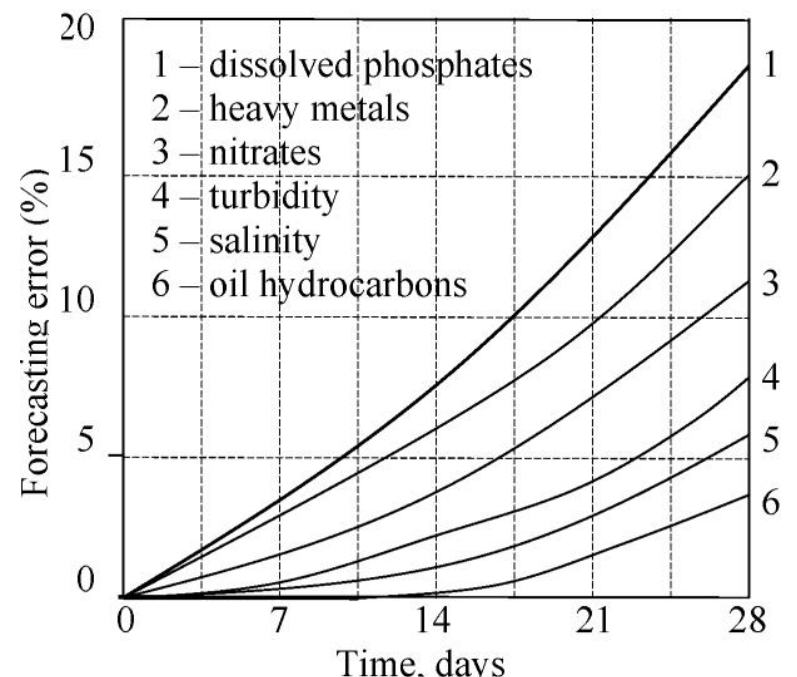

Figure 14. A correlation between the GIMS precision and temporal monitoring regime.

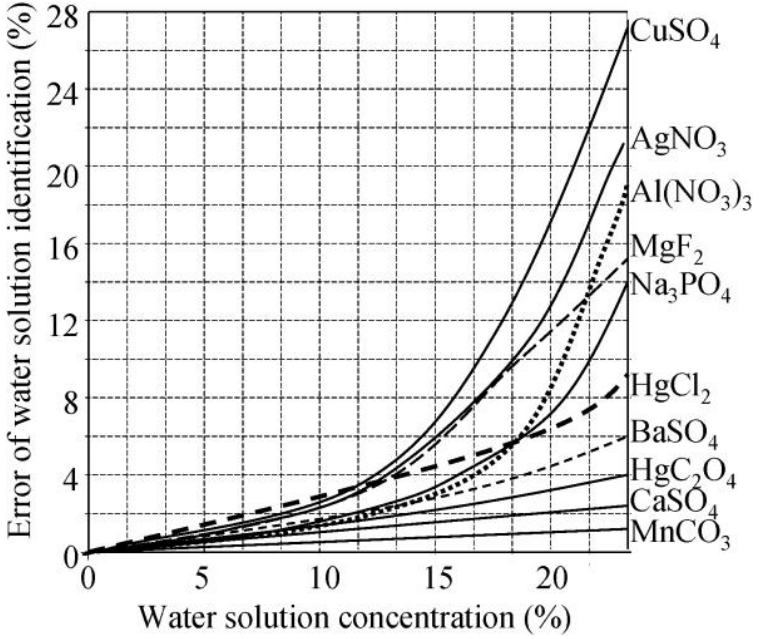

Figure 15. A depending of the GIMS precision on the water solution concentration.

\section{CONCLUSION AND DISCUSSION}

After all, the basic goal of all investigations in direction of the GIMS-technology development comes to the following tasks:

- the acceleration of optimization of expenditures on reconstruction of environment survey systems;

- creation of methods for the data reconstruction and interpretation under the conditions of geographical uncertainty of the data binding; and

- ensuring purposeful direction of global processes so that they are for the good of mankind and do not cause damage nature.

The information-instrumental tools considered in this paper are accompanied by series of mathematical algorithms for the solution of inverse tasks arising under the evaluation of environmental parameters. Particularly, detailed description on these algorithms is given by Krapivin and Shutko [1] where universal information technologies for remote monitoring of soilplant formations and aquatic systems are represented.

An experience of these tools under the solution of the wide range of problems arising in agriculture is detailed described in series of publications [2,4]. Real application of these tools was realized in different situations when applied tasks were solved. For example, using the remote-sensing platforms has allowed the solution of many applied tasks including a mapping the soil moisture in possible under-flooding zones near Danube River and leakage across the dams in the Netherlands [5].

Krapivin et al. [5] have shown that coupled use of microwave and optical tools improve the assessment of regional geoecosystem state. The GIMS technology provides the data processing and decision making concerning the monitoring regime management. Really, it is needed to solve the tasks of the hydrological system state assessment when monitoring data sets are delivered from different sources [16,17]. Moreover, combined use of microwave and optical sensors gives a 
possibility to assess the water quality with high reliability.

Finally, application fields of the GIMS-based tools include the following directions:

- Landscape and SHF-radiometric mapping of the land and water surface for different applications including melioration, hydrology, agriculture, geoecology, and epidemiology;

- Identification and diagnostics of stressful environmental situations including forest fires, flooding, and weather processes; and

- Insurance of the land and buildings using the microwave mapping of the soil water regime characteristics.

\section{ACKNOWLEDGMENTS}

This study was partly supported by the Russian Fund for Basic Research, Project No. 16-01000213-a.

\section{REFERENCES}

[1] Krapivin, V.F., Shutko, A.M. Information technologies for remote monitoring of the environment. Springer/Praxis, Chichester U.K., 2012, 498 pp.

[2] Nitu, C., Krapivin, V.F., Soldatov, V.Yu. Information-modeling technology for environmental investigations. Matrix Rom, Bucharest, Romania, 2013. $621 \mathrm{pp}$.

[3] Mkrtchyan, F.A., Krapivin V.F. GIMS - technology in the water quality monitoring. Proceedings of the International Conference on GeoInformatics for Spatial-Infrastructure Development in Earth \& Allied Sciences (GIS-IDEAS 2016). 1215 November, 2016, Hanoi, Vietnam, pp. 191196.

[4] Nitu, C., Krapivin, V.F., Mkrtchyan, F.A., Soldatov, V.Yu., Dobrescu, A.S. Multi-functional informational - instrumental technology for the hydrochemical monitoring. Proceedings of the $21^{\text {st }}$ International Conference on Control Systems and Computer Science, 29-31 May 2017, Bucharest, Romania. University POLITEHNICA of Bucharest, Romania, Vol. 1, Bucharest, Romania, pp. 715-720.

[5] Haarbrink, R., Krapivin, V.F., Krisilov, A., Krisilov ,V., Novichikhin, E.P., Shutko, A.M., Sidorov, I. Intelligent data processing in global monitoring and security. ITHEA, Sofia. 2011. 410 pp.

[6] Krapivin, V.F., Varotsos,C.A., Soldatov, V.Yu. New Ecoinformatics tools in environmental science: applications and decision-making. Springer, London, U.K., 2015. 903 pp.

[7] Krapivin, V.F., Mkrtchyan, F.A., Soldatov, V.Yu., Phillips, G.W. GIMS-based technology for vegetation microwave monitoring. Reports of the Moscow A. S. Popov Scientific-Technical Soci- ety of Radio Engineering, Electronics and Communications. Series "Ecoinformatics Problems", Issue XII, Moscow, 2016, pp. 10-17.

[8] Krapivin, V.F., Varotsos, C.A., Christodoulakis, J. Mission to Mars: Adaptive identifier for the solution of inverse optical metrology tasks. An International Journal of Solar System Science: Earth, Moon, and Planets, 2016. V.4. P. 1-14. DOI 10.1007/s11038-016-9487-0.

[9] Krapivin, V.F., Shutko, A.M., Chukhlantsev, A.,A., Golovachev, S.P., Phillips. G.W. GIMS-based method for vegetation microwave monitoring // Environmental Modelling and Software. 2006. Vol. 21. No. 3. P. 330-345.

[10] Mkrtchyan, F.A., Krapivin, V.F. About microwave radiometry and spectroellipsometric technologies for monitoring marine ecosystems. North Pacific Marine Science Organization (PICES) Annual Meeting 2016. "25 Year of PICES: Celebrating the Past, Imagining the Future". Abstracts. November 2-13, 2016, San Diego, CA, USA, pp. 276-277.

[11] Altenburger, R., Ait-Aissa, S., Antczak, P., Backhaus, T., Barceló, D., Seiler, T.B., Brion, F., Busch, W., Chipman, K., de Alda, M.L., de Aragão Umbuzeiro, G. Future water quality monitoring - adapting tools to deal with mixtures of pollutants in water resource management. Science of the Total Environment, 2015, Vol. 512513, pp.540-551.

[12] Pellerin, B.A., Bergamaschi, B.A., Horsburgh, J.S. In Situ Optical Water-Quality Sensor Networks-Workshop Summary Report. U.S. Geological Survey, Reston, Virginia: 2012, pp. 1-14.

[13] Krapivin, V.F., Mkrtchyan, F.A. Spectroellipsometric tools for the water quality diagnostics in the Sea of Okhotsk. Proceedings of the $31^{\text {st }}$ International Symposium on Okhotsk Sea \& Sea Ice, 21-24 February 2016, Mombetsu, Hokaido, Japan. The Okhotsk Sea \& Cold Ocean Research Association (OSCORA), Mombetsy, Hokkaido, Japan, 2016, pp. 101-1104.

[14] Krapivin, V.F., Mkrtchyan, F.A., Soldatov, V.Yu., Tovarnitchi V.M. An expert system for the aquatic systems investigation. Proceedings of the $21^{\text {st }}$ International Conference on Control Systems and Computer Science - CSCS21, 29-31 May 2017, University POLITEHNICA of Bucharest, Romania. Proceedings IEEE Computer Society, Conference Publishing Services (CPS), Vol. 1, Bucharest, Romania, 2017, pp. 703-707.

[15] Krapivin. V.F., Varotsos. C.A., Nghia, B.Q. A modeling system for monitoring water quality in lagoons. Water, Air \& Soil Pollution, 2017. Vol. 228 , No. 397, pp. 1-12, DOI 10.1007/s11270017-3581-4

[16] Feng, W.W., Li, D., Cai, Z.Q., Zhang, Y.C. Xu, $X$. November. An instrument for on-line chemical oxygen demand and nitrate in water monitoring. Proceedings of the SPIE/COS Photonics Asia, 2016, Vol. 10026, pp. 1002611-1002611. 
[17] Vasilescu, A., Suciu, G., Suciu, V. Monitoring the Danube with Adcon Telemetry Equipment - a Case Study for OTT Hydromet and Rowater Company // Proceedings of the 2nd International
Conference on "Water Resources and Wetlands", WATER2014, Vancouver, 2014, pp. 221-230. 